\title{
O canto das Sereias e a embriaguez \\ DO TRADUTOR
}

\section{THE SiRENS' CALL AND THE INEBRIETY OF THE TRANSLATOR}

\section{Izabela Leal}

Universidade Federal do Pará

Belém, Pará, Brasil

\section{Resumo}

Sabemos que para os românticos alemães a tradução tem um caráter fundador, estando associada ao próprio conceito de Bildung, como já assinalava Antoine Berman. A Bildung remete necessariamente à dimensão da experiência, processo de desdobramento e alargamento que encontra uma metáfora perfeita na noção de viagem, tão cara aos românticos. Tal movimento de travessia que constitui a inquietante "tarefa do tradutor" pode ser entendido como uma navegação por essa região nebulosa onde se ouve o canto das Sereias e, como pensava Maurice Blanchot, corre-se o risco do desaparecimento.

\begin{abstract}
It's well known that to German Romantic culture translation is related to the process of formation, being associated with the very concept of Bildung, as already pointed out by Antoine Berman. Bildung necessarily refers to the dimension of experience, a process of enlargement and unfolding, which is a perfect metaphor to the notion of travel, so important to the Romantics. Such movement of crossingover, which is the unsettling "task of the translator", can be understood as a process of navigation through that nebulous region where one hears the Sirens' call, and as Maurice Blanchot once wrote, one runs the risk of disappearing.
\end{abstract}

\section{Résumé}

Nous savons que, pour les romantiques allemands, la traduction a un caractère fondateur, étant associée au concept même de Bildung, comme le signalait déjà Antoine Berman. La Bildung renvoie forcément à la dimension de l'expérience, processus de dédoublement et d'élargissement qui trouve sa parfaite métaphore dans la notion de voyage, si chère aux romantiques. C'est un tel mouvement de traversée qui constitue l'inquiétante "tâche du traducteur», et il peut être compris comme une navigation sur cette nébuleuse région où l'on entend le chant des Sirènes et où, comme le pensait Maurice Blanchot, l'on risque de disparaître.
Palavras-chave: Tradução; linguagem; voz; poesia moderna.

Keywords: Translation; language; voice; modern poetry.

Mots-clés: Traduction; langage; voix; poésie moderne. 
* (CAMPOS, Haroldo de. "A palavra vermelha de Hölderlin". In: A arte no horizonte do provável. São Paulo: Perspectiva, 1975: 93-107.)

* (BENJAMIN, Walter. "A tarefa do tradutor". In: Escritos sobre mito e linguagem. São Paulo: editora 34, 2011: 101-119.)

* (CAMPOS, Haroldo de. Galáxias. São Paulo: Editora Ex-Libris, 1984)

* (CAMPOS, Haroldo de. "A palavra vermelha de Hölderlin". In: A arte no horizonte do provável. São Paulo: Perspectiva, 1975: 99) então propus aquela frase uma achega à teoria das cores ismênia falando du scheinst ein rotes wort zu faerben pela voz de sófocles pela voz de hölderlin schiller rindo goethe sorrindo ilustre companhia estaria maluco herr hölderlin ou se fingia de pois sófocles só queria dizer tu pareces preocupada com algo ismênia a antígone pela voz de sófocles um dos mais burlescos produtos do pedantismo aquela fala tinta de vermelho do senhor hölderlin e no entanto e no entempo e no intenso o mar purpurescia em kalkháinous' épos polipurpúreo mar de fúria polivermelho mar guerreiro [...]

(Haroldo de Campos)

O famoso episódio das traduções de Sófocles realizadas por Hölderlin funcionou desde sempre, na construção do pensamento de Haroldo de Campos, como uma espécie de pilar para a sua teoria da tradução. No ensaio "A palavra vermelha de Hölderlin", ${ }^{*}$ Campos afirma enxergar, justamente na incompreensão de que tais traduçôes foram alvo, a derrocada de toda uma concepção literária e a fundação da modernidade poética. A polêmica em torno desse caso é bastante conhecida, passando inclusive pelas consideraçōes de Walter Benjamin no ensaio sobre "A tarefa do tradutor", * no qual tais "criaçōes" são valorizadas e apontadas como arquétipos de toda tradução. Interessa-me, nesse sentido, pensar como as traduçōes hölderlinianas exibem, por excelência, esse lugar poético da modernidade e também o próprio lugar contemporâneo da tradução, lugar esse ilustrado com ironia, ainda que poética, a partir da reconstrução que Haroldo de Campos faz da cena que envolvia os principais nomes da Alemanha do século XVIII, no fragmento 23 de Galáxias citado acima.*

Em primeiro lugar, gostaria de chamar a atenção para a estratégia empregada por Haroldo na elaboração desse fragmento. Retomando uma passagem de seu próprio ensaio, o autor faz uma menção ao filólogo Wolfgang Schadewaldt, que, segundo ele, associou o verbo grego "kalkháino" "à cor vermelho-escura que assume o mar quando está próxima uma tempestade".* Por esse viés, o mar e a viagem - temas recorrentes nos fragmentos de Galáxias como lugar de evocação de uma travessia muito emblemática, a Odisseia - se introduzem numa discussão que aparentemente dizia respeito apenas a um problema de tradução. No entanto, parece-me evidente que o "épos polipurpúreo mar de fúria polivermelho mar guerreiro" remete imediatamente à Odisseia, numa conjunção que 
reúne a palavra, o mar, a viagem, a guerra e, por último, a loucura. Aí está, a meu ver, apresentado na recorrência de determinadas imagens e metáforas, o pano de fundo dos estudos contemporâneos sobre tradução. Não por acaso, o riso de Goethe ecoa também no belíssimo "Traduire",* de Maurice Blanchot, no qual o autor se refere a Hölderlin como um homem que já não era nem poeta nem tradutor, para concluir, com certa malícia, que traduzir no final das contas é loucura.

Se o épos marítimo concretizou-se no fragmento de Galáxias a partir de um problema de tradução, isso significa que de fato a "tarefa do marinheiro" diz algo a respeito daquela do tradutor, que por sua vez indica o lugar do poeta moderno. "Mestre das passagens e dos intervalos", como assinala Jeanne Marie Gagnebin, ${ }^{*}$ o tradutor é precisamente aquele que tem de atravessar um oceano, oceano da linguagem - ou martexto das Galáxias haroldianas -, abandonando a sua terra natal, a sua língua materna, em direção ao desconhecido, ao país estrangeiro, à língua do original. Ele está constantemente em trânsito, trânsito entre línguas e culturas, trânsito entre textos. Nenhuma terra lhe serve de abrigo. E, no entanto, uma vez começada a viagem, uma vez iniciado o percurso pelo território alheio, é preciso retornar ao lar: retorno à cultura própria, à língua materna, mesmo sabendo que ela não será mais a mesma. $\mathrm{Na}$ escrita, trata-se sempre de retorno, retorno da diferença, bem entendido. Vem daí o fato de a tradução ser tomada como o modelo de toda e qualquer criação literária, no qual a experiência da literatura é sempre a experiência de uma repetição inaugural, como afirma Lacoue-Labarthe numa entrevista que tem como ponto de partida as traduções por ele realizadas de Hölderlin para o francês.*

Por outro lado, o tema da viagem, tão caro aos românticos alemães, pode ser associado ao conceito fundamental de Bildung. Como sublinha Antoine Berman, a própria ideia de tradução para os românticos estaria inscrita na Bildung, apontando para a sua dupla acepção de cultura e processo de formação:

[...] a Buildung é um autoprocesso em que há um "mesmo" que se desdobra até adquirir sua plena dimensão. É provável que o conceito mais elevado que o pensamento alemão da época tenha criado para interpretar esse processo seja o da experiência [...]. Pois a experiência é a única noção que pode abraçar todas as outras. É viagem, Reise,
* (BLANCHOT, Maurice

"Traduire". In: L'amitié. Editions Gallimard: Paris, 1971)

* (GAGNEBIN, Jeanne Marie. "Prefácio". In: LAGES, Susana Kampff. Walter Benjamin: Tradução e melancolia. São Paulo: EDUSP, 2007: 14.)

* (LACOUe-labarthe, Philippe. "De Hölderlin à Marx: mythe, imitation, tragédie". In: Labyrinthe, n. 22, 2005: 121-133.) 
* (BERMAN, Antoine. A prova do estrangeiro: cultura e tradução na Alemanha romântica. Bauru: EDUSC, 2002.)

* (LAGES, Susana Kampff. Walter Benjamin: Tradução e melancolia. São Paulo: EDUSP, 2007.) ou migração, Wanderung. Sua essência é jogar o mesmo numa dimensão que vai transformá-lo. Ela é o movimento do "mesmo" que, mudando, encontra-se outro.*

Apesar dessas possíveis ressonâncias, o movimento de viagem que quero discutir aqui é um pouco mais radical, pois o que me interessa particularmente é uma certa tensão entre a viagem e a impossibilidade do retorno, ou, formulando o problema de outro modo, a função que a iminência da morte ${ }^{1}$ desempenha para que a viagem se constitua como uma determinada experiência.

É bem verdade que toda viagem implica riscos, derivas, desvios, adiamentos. O retorno ao lar nem sempre se realiza de forma pacífica e pouco acidentada. Pensando em termos práticos e empíricos no campo da tradução, com frequência lemos a respeito de tradutores que passaram dez ou vinte anos - uma odisseia particular - traduzindo uma única obra. Há outros casos, mais graves, em que o tradutor naufraga completamente nesse mar de línguas. A obra não se produz, a tarefa é abandonada. Mas evidentemente também não é isso que quero discutir aqui, não se trata de uma questão meramente prática ou temporal...

De todo modo, se penso num certo naufrágio do tradutor, evoco imediatamente a velha questão das perdas e ganhos que decorrem do ato de traduzir. Essa dimensão da perda propriamente dita não se afasta da famosa melancolia, tão bem estudada no livro de Susana Lages, ${ }^{*}$ que a acompanha como uma espécie de sombra. O fracasso, no sentido da visão melancólica, apoia-se na impossibilidade de recuperar completamente o objeto original, tornando o texto traduzido, ele também, uma espécie de sombra do texto estrangeiro. Mas aqui, novamente, o que quero perseguir não é essa dimensão melancólica da tradução. Se há naufrágio - e penso também na palavra "derrota", em seu duplo sentido: "percurso, rota, caminho" e também "insucesso" -, é necessário que essa derrota seja entendida mais na primeira acepção do que na segunda. Trata-se antes de um percurso arriscado, de gozo e de desaparecimento, de atração, mas de uma atração perigosa, uma atração fatal. Mas de que se trata, enfim? É a essa outra natureza de problema que tentarei responder, a isso que chamo de "embriaguez do tradutor", uma

\footnotetext{
${ }^{1} \mathrm{~A}$ iminência na morte pode se apresentar de várias formas diferentes, como, por exemplo, o naufrágio ou o apelo das Sereias na Odisseia.
} 
embriaguez decorrente da própria natureza desidentitária do projeto, embriaguez da linguagem.

Convoco aqui o poeta belga Henri Michaux, que em seu livro Qui je fus nos fala dessa associação entre tradução e viagem num poema intitulado justamente "Traduction", ${ }^{*}$ ao qual recorro para refletir sobre o estatuto da poesia moderna e, obviamente, da tra* (MICHAUX, Henri. Qui je fus. Paris: Gallimard, dução:

Traduction

Je me blague et me siroule

Dans le fond je me déruse

Rien ne tient bon; j'ai beau regarder

Ça s'erfule et se range

Clermont sonne et Ferrand répond

Sottes rues satisfaites, ça promet

Mais, que s'isolent les envieux et les torbus itou

Laisse donc pérousser les aigres maigres

Pour moi je retourne à l'eau de l'océan. Adieu

J'ai entendu le claquerin des paquebots; j'embraque

Or, vieille habitude; j'y suis peu de chose; mais j'ai

dans mes doigts la façon de douze

noeuds de matelots et faire babord

tribord sur mes jambes, j’aime ça.

Par très mauvais temps je m'agrippe au grand pelé,

l'oreille contre, ça fait toutes sortes de

bruits; entre deux rafales je regarde

venir les houlons crêtés de sabrouse

et puis parfois cette grosse eau se fait si calme et

comme agonisante, on se

sent profondément heureux

à peine si elle craquèle de quelques rides et plis,

comme ce qui tient et broquetille sous l'oeil d'une

vielle femme. ${ }^{2}$

\footnotetext{
${ }^{2}$ Cito aqui a tradução de Herberto Helder: "Eu me escarneço e saboreio/ Tornome de fato inocente/ Nada resiste; olho em vão/ Isto circula e entra na ordem/ Um sítio chama outro responde/ Tolas ruas contentes, oh como a coisa promete/ Mas que se afastem os invejosos e os retorcidos aspas idem/ Deixa pois perorempurrar os agros magro / Pelo meu lado regresso à água do oceano. Adeus/ Ouvi o pancadaquear dos paquetes, eu embarco/ Ora pois, velho hábito; pouco valho; mas tenho nos dedos/ o jeito dos marinheiros de dar doze nós/ numa corda e bombordo estibordo/ balançar-me nas pernas, gosto disso./ Nas tempestades agarro-me ao grande mastro nu, /ouvido colado, há todo o tipo de ruídos;/entre duas rajadas vejo virem os vagalhões com as cristas espumadas/e às vezes esta água violenta torna-se tão calma e/como que agonizante, sentimo-nos profundamente felizes/ se ela apenas se agita com algumas rugas e dobras,/ como algo que se aguenta temte-não caias sob uns/ velhos olhos benevolentes e sábios de mulher." (HELDER, Herberto. Doze nós numa corda. Lisboa: Assírio \& Alvim, 1997.)
} 
Em primeiro lugar, gostaria de ressaltar que, se o título do poema é tradução, não há nada que nos permita evocar imediatamente a imagem do tradutor, mas somente a do marinheiro, cujo caráter de instabilidade vem assinalado desde o primeiro verso por uma espécie de distanciamento irônico de si (je me blague), como também pelo neologismo siroule, que logo comentarei. O poema, como bem se observa, está coalhado de neologismos, típicos da escrita de Michaux, denunciando a presença da oralidade, ou talvez remetendo às gírias dos marinheiros. Lembremos que Michaux alistou-se na marinha mercante francesa, tendo viajado pelas Américas durante esse período. A tradução, no entanto, é o que está fora do poema, em seu título, e que por esse caráter exterior o reconfigura, dando a ver o canto entoado a partir de uma terra estranha, no qual tradução e viagem aparecem ligadas de forma indissociável.

Farei, de início, alguns comentários a respeito dos neologismos criados por Michaux, mais especificamente em relação àqueles que me interessam por restituírem uma proximidade entre viagem e tradução. No primeiro deles, "siroule", é possível escutar a união de dois verbos, "siroter" e "rouler". O verbo "siroter" corresponde a "saborear" em português. Já "rouler" abre um campo bem maior de possibilidades. Dentre as várias acepções de rouler, destaco duas diretamente relacionadas à viagem, e é claro que estou pensando aqui mais uma vez na viagem de Ulisses: ${ }^{3}$ a primeira delas evoca o balanço do barco feito pela ondulação da água, balançar, oscilar, e a segunda remete à ideia de errância presente em qualquer viagem, rouler é errar permanentemente, perder-se sem cessar, tal como aconteceu com Ulisses em seu retorno a Ítaca.

O segundo neologismo permite novamente uma evocação da Odisseia: o substantivo "ruse", que forma o verbo "déruser", indica "ardil", substantivo que remete inegavelmente ao famoso atributo do herói da epopeia: sua astúcia. Mas, aqui, esse substantivo ganha um prefixo de negação, indicando uma estratégia de "desardilação". Nos outros neologismos não foi possível recuperar essa relação mais direta, mesmo assim em geral eles remetem ao tema marítimo.

$A$ evocação da Odisseia percorre todo o poema - o "velho hábito" de viajar e os "doze nós numa corda" que o poeta/mari-

\footnotetext{
${ }^{3}$ Retomando o estudo de Pietro Boitani, lembro que ao convocar o lugar literário da viagem estamos sempre convocando essa primeira viagem fundadora da cultura ocidental. (BOITANI, Pietro. A sombra de Ulisses. São Paulo: Perspectiva, 2005.)
} 
nheiro precisa dar para agarrar-se "ao grande (mastro) nu" e estar atento a "todo tipo de ruídos", inclusive ao canto das Sereias. Assinalo, nesse sentido, que tive um primeiro contato com o poema pelas mãos do poeta português Herberto Helder, ${ }^{4}$ que o escolheu para abrir um de seus livros de traduções, cujo título, Doze nós numa corda, apresenta mais uma referência ao poema de Michaux, justamente à passagem da Odisseia em que Ulisses escuta o canto das Sereias. O tradutor é, então, um novo Ulisses, pois em sua viagem pelas terras estrangeiras ele corre o risco de ouvir um canto inumano, de ser atraído para essa região onde o que se encontra é apenas a absoluta mudez da morte, onde não há nada a fazer senão sucumbir ao canto das Sereias. E, assim como Ulisses, o tradutor é aquele que quer ouvir o canto estrangeiro, lugar da pura diferença e ao mesmo tempo da mais completa harmonia entre as línguas, lugar em que todo e qualquer sentido se desfaz, como já observava Walter Benjamin ao elencar justamente Hölderlin como o verdadeiro modelo de tradutor por ter se afastado de uma exigência do sentido em prol de uma pura harmonia entre o grego e o alemão. Não é à toa que um filófoso do peso de Lacoue-Labarthe tenha se auto incumbido de traduzir as traduções de Hölderlin. ${ }^{5}$ Certamente, é uma atividade arriscada, e o próprio Benjamin já alertava para "o monstruoso perigo originário de toda tradução: que se fechem as portas de uma língua tão ampliada e reelaborada, encerrando o tradutor no silêncio."*

Mas aquilo para quê Benjamin alertava como um perigo mortal era, paradoxalmente, o que a tradução, e mais ainda, a poesia moderna, buscam incessantemente realizar. Trata-se da busca desse lugar no qual tradutor e poeta podem se desincumbir do peso do sentido, lugar de um encantamento originário, lugar também de pura indiferenciação. É nele que se dá a promessa de criação, o advento do poema. O canto das Sereias, nas palavras de Foucault, é precisamente a instância que anuncia o poema por vir:

\footnotetext{
${ }^{4}$ Ao longo de sua vida, Herberto Helder dedicou cinco livros à tradução de poemas, que ele chamava de "poemas mudados para português". No caso de Doze nós numa corda, o poema de Michaux está apresentado em versão bilíngue, o que raramente acontece no projeto tradutório herbertiano, onde a presença do original é comumente apagada.

${ }^{5}$ Assumindo uma postura contrária ao preceito de Benjamin em "A tarefa do tradutor", Lacoue-Labarthe traduziu a Antigone em 1977/1978.
}

* (BENJAMIN, Walter. "A tarefa do tradutor". In: Escritos sobre mito e linguagem. São Paulo: editora 34, 2011: 119.) 
* (FOUCAULT, Michel. Ditos e escritos III. Estética: literatura e pintura, música e cinema. Rio de Janeiro: Forense universitária, 2001.)

* (NANCY, Jean-Luc. Listening. New York: Fordham University Press, 2007. Translated by Charlotte Mandell.)

* (ZUMTHOR, Paul. Introdução à poesia oral. Belo Horizonte: Ed. UFMG, 2010.)
Sua música é o contrário de um hino: nenhuma presença cintila em suas palavras imortais; somente a promessa de um canto futuro percorre sua melodia. Aquilo com que elas seduzem não é tanto o que fazem ouvir, mas o que brilha no longínquo de suas palavras, o futuro do que elas estão dizendo. Seu fascínio não nasce do canto atual, mas do que ele se propóe a ser. Ora, o que as Sereias prometem cantar para Ulisses é o passado de suas próprias proezas, transformadas para o futuro em poema $[. . .]^{*}$

É bem verdade que a lição que aprendemos com a Odisseia é que Ulisses só se torna verdadeiramente cantor, cantor de suas próprias aventuras, bem entendido, depois de ter ouvido o canto inumano das Sereias. De todo modo, gostaria de pensar um pouco além do que afirma Foucault quando diz que "nenhuma presença cintila em suas palavras imortais”. Pois se há aqui um esvaziamento do canto atual e uma promessa do canto futuro, não me parece irrelevante pensar o que havia na voz das Sereias para além da promessa que elas anunciavam. Presença que se faz mais visível não talvez nas sereias de Homero, mas naquelas que o poeta moderno continua a ouvir. Nesse sentido, faço minha a interrogação de Jean-Luc Nancy no ensaio que se intitula precisamente Listening: "que segredo está em jogo quando alguém realmente escuta, isto é, quando alguém tenta capturar ou surpreender a sonoridade mais do que a mensagem?" $6 *$

E aqui seria preciso pensar a voz como uma espécie de suporte da enunciação que tende a desaparecer por trás do sentido que enuncia, aquilo que faz com que Paul Zumthor pense a voz como coisa material: "Anterior a toda diferenciação, indizibilidade apta a revestir de linguagem, a voz é uma coisa".* Ou seja, para além daquilo que é propriamente liguagem, há uma dimensão implícita da da materialidade da voz, aquilo que na voz não remete ao sentido, que é pura ressonância, pura invocação, silêncio e morte. Pois bem, para Michaux, escrever é entregar-se diretamente a essa embriaguez do canto, e aqui "l'oreille contre" remete aos ouvidos em alerta, atentos, como se estivessem realmente aplicados sobre alguma coisa, sendo que a única coisa sobre a qual eles se aplicam é à própria materialidade da voz das Sereias, ao seu timbre, seu tom. ${ }^{7}$

\footnotetext{
${ }^{6}$ No original em inglês: What secret is at stake when one truly listens, that is, when one tries to capture or surprise the sonority rather than the message?

${ }^{7}$ Não deixa de ser interessante compararmos duas traduções dessa passagem da Odisseia. A dimensão material da voz das Sereias nem sempre se torna visível, assumindo um sentido mais abstrato ou sendo traduzida por canto. Basta compa-
} 
Há aqui uma orelha extremamente unida ao ruído mortal, capturada por essa loucura poética, a ponto de o estranhamento causado na própria língua tornar-se também um desfazimento da identidade, ainda que incompleto. Lembro aqui a loucura de Hölderlin, que Benjamin, de forma sutil, associa à última obra produzida pelo poeta, justamente as traduções de Sófocles, nas quais a linguagem tende a esse esvanecimento do sentido. Do mesmo modo, evoco também a passagem de uma carta de Michaux ao seu editor na qual, depois de ter passado anos viajando, escreve: "Não compreendo mais francês."*

O tradutor, como o projeto de Hölderlin evidencia, precisará manter-se nesse lugar tenso, em que ouve o canto, o chamado do exterior, mas continua agarrado ao mastro com os "doze nós numa corda”, ou seja, à sua língua natal. Nessa região oceânica que é a própria escrita, a poesia assemelha-se a um chamado do exterior, o canto das Sereias, como pensa Blanchot, que conduz os navegantes ao abismo de uma voz inumana, estranha aos ouvidos mortais, "canto do abismo que, uma vez ouvido, abria em cada fala uma voragem e convidava fortemente a nela desaparecer”.* Mas, se o poeta sucumbe, de fato, ao "canto das Sereias", nenhuma escrita se faz possível, o que significa que se ele continua a escrever é porque, de alguma forma, renunciou, pelo menos em parte, a esse chamado do exterior, um pouco como Ulisses, que se utiliza de um ardil para poder ouvir o canto e sobreviver a ele. No entanto, é preciso lembrar que Michaux, situado na modernidade poética, começa falando numa "desardilação", "je me déruse", e a partir daqui há algo que se quer enunciar para além da possível relação com a alteridade, da tensão entre a permanência da identidade e o impulso de dissolução. Se é bem verdade que Ulisses, após ouvir o canto das Sereias, torna-se ele próprio o cantor de suas aventuras, o que ocorre é ainda

rar a tradução de Trajano Vieira, a de Haroldo de Campos e a tradução em prosa de Carlos Alberto Nunes, ficando evidente que apenas a primeira aponta para as qualidades materiais da voz: Trajano Vieira menciona duas vezes essa dimensão mais material da voz, o tom, o timbre: "[...] O ingênuo que de perto escute o timbre/ de suas vozes, nunca mais terá por perto/ a esposa e os filhos novos [...]" (XII, 40-42) e também "[...] Devo ouvir sozinho/ o tom de sua voz" (XII, 160161) (HOMERO. Odisseia. Trad. de Trajano Vieira. São Paulo: Ed. 34, 2011). Já a de Carlos Alberto Nunes: "Quem quer que, por ignorância, vá ter às Sereias, e o canto/ delas ouvir, nunca mais a mulher nem os tenros filhinhos/ hão de saudá-lo contentes [...]" (XII, 41-43), e "Somente a mim concedeu que as ouvisse" (XII, 160) (HOMERO. Odisseia. Trad. de Carlos Alberto Nunes. Rio de Janeiro: Ediouro, 2001).
* (BELLOUR, Raymond e TRAN, Ysé. "Chronologie". In: Magazine Littéraire, $\mathrm{n}^{\circ}$ 364, abril 1998: 18-24.)

* (BLANCHOT, Maurice. O livro por vir. São Paulo: Martins Fontes, 2005: 4.) 
uma passagem do imediato, o puro gozo da escuta de um canto inaudível, à mediação, a fruição narrativa. De todo modo, Ulisses retorna à pátria, à família, ao leito nupcial. ${ }^{8}$

No caso de um projeto poético moderno como o de Michaux, a desardilação torna-se aquilo que é impossível e necessário, pois no limite do apagamento do sentido da linguagem o que se encontra é ainda o retorno do sentido, o seu recomeço. O "velho hábito" é mais uma vez a inscrição do recomeço, ainda a navegação, ainda um retorno, mas não mais um retorno à pátria e à língua natal, mas apenas um retorno ao momento em que se inicia a escrita. $O$ poema de Michaux, a meu ver, é um poema in medias res, pois já começa com o poeta embriagado pelo canto das Sereias, sendo que essa viagem à qual ele agora se dedica não passa de uma renovada tentativa de dissolução, a perseguição do imediato, sempre desejada e adiada, que se efetua no movimento circular da própria escrita, na eterna repetição. Aí está, talvez, a principal diferença entre a poesia clássica e a moderna. Na poesia clássica o poeta lança mão de um ardil que lhe permite enganar o outro; ele pode se embriagar do canto das Sereias e retornar ao lar. Na poesia moderna o poeta sem ardil não pode mais enganar ninguém; engana, quando muito, a si próprio. E, se ele se embriaga do canto das Sereias, fica eternamente condenado à promessa de um poema que não se realiza, de um retorno à origem que não pode se concretizar. Ou enlouquece.

Izabela Leal é professora de Literatura Portuguesa da Universidade Federal do Pará, pesquisadora e tradutora. É coorganizadora do livro Tradução literária: a vertigem do próximo (Azougue, 2011) e coautora de Camilo Pessanha em dois tempos (7Letras, 2006).

E-mail: <izabelaleal@gmail.com>

${ }^{8} \mathrm{O}$ leito, inclusive, é o signo distintivo que revela a identidade de Ulisses à esposa. 